\title{
Cessation of embolic signals after antithrombotic prevention is related to reduced risk of recurrent arterioembolic transient ischaemic attack and stroke
}

\author{
M Goertler, T Blaser, S Krueger, K Hofmann, M Baeumer, C-W Wallesch
}

J Neurol Neurosurg Psychiatry 2002;72:338-342

See end of article for authors' affiliations

Correspondence to: Dr M Goertler, Department of Neurology, University of Magdeburg, Leipziger Strasse 44, D-39120 Magdeburg, Germany: michael.goertler@medizin. uni-magdeburg.de

Received 24 July 2001

In revised form

5 November 2001

Accepted

8 November 2001

\begin{abstract}
Objectives: To evaluate the reduction of embolic signals after the initiation of an antithrombotic secondary prevention in patients with recent arterioembolic stroke and to determine the predictive value of decreased microembolism on the risk of early stroke recurrence.

Methods: Eighty six consecutive patients (55 men, 31 women; mean age 60.6 years) with a non-disabling arterioembolic ischaemic event in the anterior circulation within the last 30 days and a medium grade or high grade stenosis $(\geqslant 50 \%)$ of the ipsilateral carotid or middle cerebral artery underwent 1 hour transcranial Doppler monitoring as part of the admission examinations. Antithrombotic secondary prevention was started after completion of admission. Patients in whom embolic signals were detected underwent a second monitoring within 4 days (mean time 1.8 days). All patients were followed up prospectively to evaluate the relation between presence and persistence of embolic signals and the risk of recurrent transient ischaemic attack (TIA) and stroke within the next 6 weeks.

Results: In 44 patients, embolic signals were detected at admission, a mean 5.4 days (range 0 to 21 days) after the initial event. Twenty five were positive for embolic signals also at the second monitoring, in 19 signals had ceased. Forty two patients without embolic signals at admission served as controls. During follow up, six ischaemic events (two stroke, three TIA, one amaurosis fugax) occurred in 25 patients with persisting embolic signals but none in 19 patients in whom signals had ceased by the second monitoring. One patient in the control group had a TIA. The incidence of a recurrent event was 0.45 per 30 patient-days if embolic signals persisted compared with 0.015 if signals could not be detected or had ceased. Persistence of embolic signals was an independent predictor of a recurrent TIA or stroke (adjusted odds ratio $37.0 ; 95 \%$ confidence interval $(95 \% \mathrm{Cl}) 3.5$ to $333 ; \mathrm{p}<0.003)$. Cessation and decrease of embolic signals was associated with the administration of antiplatelet agents but not with anticoagulation with intravenous heparin $(p<0.001)$.

Conclusions: Rapid cessation of embolic signals detected in patients with recently symptomatic arterial stenosis decreases increased risk of an early ischaemic recurrence. Effect of antithrombotic agents on embolic signals might serve as a marker for their efficacy on preventing stroke recurrence.
\end{abstract}

li n patients with symptomatic arterial stenosis, stroke is most likely caused by emboli arising from the stenotic lesion. Subsequent antithrombotic therapy aims to prevent recurrent thromboembolism. However, even in the presence of an antithrombotic prevention, recurrence of an ischaemic event within the first month has been described in $10 \%$ to $15 \%$ of patients. ${ }^{12}$ Presence of microemboli as detected by transcranial Doppler sonography (TCD) after an initial event has been reported as an independent predictor of an early ischaemic recurrence with a ninefold increase of risk, ${ }^{2}$ and was associated with the absence of an antiplatelet medication. ${ }^{3}$ These findings suggest a common pathophysiology of clinically symptomatic embolism and clinically silent particulate microemboli, both probably reflecting a still active emboligenic process at the site of the stenotic lesion. This assumption is supported by a few case studies which followed up patients by repeated clinical and TCD examinations, in which the frequency of embolic signals reflected the course of recurrent ischaemic symptoms. ${ }^{4-7}$ We therefore hypothesised that embolic signals may be used as a marker of the efficacy of secondary prevention - that is, that a reduction of signals by an antithrombotic therapy is accompanied by a reduction of risk for an early stroke recurrence in patients with recently symptomatic arterial stenosis.

In the study presented here, we monitored the effect of an antithrombotic prevention on embolic signals in consecutive patients with a recent arterioembolic ischaemic event. We prospectively followed up these patients to determine the predictive value of a decrease of signals on the risk of stroke recurrence.

\section{SUBJECTS AND METHODS}

Eighty six patients (55 men, 31 women; mean age 60.6 (SD (13)) years) with a recent ( $\leqslant 30$ days) arterioembolic stroke in the anterior circulation who underwent a l hour TCD monitoring at admission were eligible for the study. Fifteen had had amaurosis fugax, 34 a transient ischaemic attack, and 37 a minor stroke a mean 7.3 days (range 0 to 30 days) earlier. Eligible patients were selected from a series of 238 consecutive cases presented at the Department of Neurology, Magdeburg University, with a non-disabling ischaemic event in the anterior circulation within the past 30 days, a medium grade or high grade stenosis of the ipsilateral carotid or middle cerebral artery (MCA), and without findings associated with cardioembolic stroke-for example, atrial fibrillation, cardiomyopathy, acute myocardial infarction, and prosthetic valve. Patients

Abbreviations: TCD, transcranial Doppler sonography; MCA, middle cerebral artery; ASA, acetylsalicylic acid; ES, embolic signals; TIA, transient ischaemic attack 
Table 1 Cessation or persistence of embolic signals after antithrombotic treatment in characteristics of patients positive for embolic signals at entry

\begin{tabular}{llll} 
& $\begin{array}{l}\text { Cessation of } \\
\text { embolic signals }\end{array}$ & $\begin{array}{l}\text { Persistence of } \\
\text { embolic signals }\end{array}$ & p Value \\
\hline Patients & $19(100)$ & $25(100)$ & \\
Sex, male & $11(58)$ & $17(68)$ & 0.71 \\
Age (y (mean (SD))) & $56.3(11)$ & $61.6(15)$ & 0.063 \\
Hypertension & $9(47)$ & $16(64)$ & 0.42 \\
Diabetes & $3(16)$ & $6(24)$ & 0.71 \\
Hypercholesterolaemia & $5(26)$ & $9(36)$ & 0.72 \\
Smoker & $9(47)$ & $6(24)$ & 0.071 \\
Hemispheric (non-ocular) symptoms & $18(95)$ & $20(80)$ & 0.21 \\
Persistent (non-transient) symptoms & $11(58)$ & $14(56)$ & 1.00 \\
Recurrent initial ischaemic events & $12(63)$ & $13(52)$ & 0.67 \\
Preexisting ASA prevention & $6(32)$ & $5(20)$ & 0.49 \\
Subcortical infarction $\leqslant 15$ mm & $5(26)$ & $7(28)$ & 0.98 \\
Territorial infarction & $9(47)$ & $11(44)$ & 0.98 \\
Extracranial stenosis (non- intracranial) & $12(63)$ & $19(76)$ & 0.55 \\
High grade stenosis (non- medium-grade) & $12(63)$ & $17(68)$ & 0.99 \\
Ischaemia to 1 ${ }^{\text {st }}$ TCD (days (mean (range))) & $5.3(0.3-17.4)$ & $5.4(0.3-21.6)$ & 0.86 \\
Embolic signals/h at 1st TCD (mean (range)) & $12.1(1-29)$ & $17.2(1-57)$ & 0.74 \\
1st TCD to treatment (h (mean (range)) & $5.6(1.0-46.5)$ & $2.4(1.0-11.7)$ & 0.83 \\
Treatment to 2nd TCD (days (mean (range))) & $1.9(0.02-3.9)$ & $1.7(0.02-3.9)$ & 0.40 \\
\hline Values are frequency (\%) unless otherwise stated. ASA, acetylsalicylic acid; TCD, transcranial Doppler.
\end{tabular}

Table 2 Interaction between risk factors and early recurrence of ischaemic events in 86 patients with recently symptomatic arterial stenosis. Cox regression

\begin{tabular}{llll}
\hline Risk factor & Odds ratio & $95 \% \mathrm{Cl}$ & $\mathrm{p}$ Value \\
\hline Age (y) & 1.022 & 0.949 to 1.101 & 0.564 \\
Time since initial ischaemic event (days) & 0.768 & 0.556 to 1.062 & 0.111 \\
Stroke as initial ischaemic event (n) & 0.300 & 0.040 to 2.242 & 0.241 \\
Recurrent initial ischaemic event (n) & 1.631 & 0.263 to 10.101 & 0.599 \\
Extracranial (non-intracranial) stenosis (n) & 1.362 & 0.185 to 10.000 & 0.762 \\
High grade (non-medium grade) stenosis (n) & 1.704 & 0.278 to 10.417 & 0.744 \\
Persistence of embolic signals (n) & 37.037 & 3.534 to 333 & 0.003 \\
\hline
\end{tabular}

were not included if 1 hour TCD monitoring could not be performed at admission - that is, insufficient temporal bone windows not allowing transcranial insonation $(n=50)$, patients rejecting the examination $(n=7)$, when the device was not available $(\mathrm{n}=\mathrm{ll})$, or when outpatient management did not allow time consuming monitoring $(n=42)$. Six patients were excluded because exhausted Doppler carbon dioxide reactivity suggested haemodynamic rather than embolic stroke pathology. ${ }^{89}$ Of the remaining 122 patients with probable arterioembolic stroke and 1 hour TCD monitoring at admission, 36 were excluded from the investigation because antithrombotic prevention had been initiated or modified (by a pre-existing medication) before the initial monitoring. This might have influenced the spontaneous rate of embolic signals so that they no longer reflected the emboligenic status of the stenosis at the time of the ischaemic event. ${ }^{3}$ Overall, included patients were younger (mean age $61 v 67$ years), less often diabetic (24v40\%), under antiplatelet prevention (47v65\%), and more often had transient (57v 42\%) and recurrent ( $42 v$ $17 \%)$ ischaemic events than excluded patients. In addition, patients excluded because of transtemporal bone window failure more often were women ( $56 v 36 \%$ ) and had medium grade stenosis ( $70 \vee 48 \%$ ), and patients in whom monitoring could not be arranged (in the majority presented from regional physicians and hospitals for ambulant reference sonography) were examined later after the ischaemic event (median, $7.7 v 3.8$ days) than selected ones.

Selected patients underwent a standardised admission and follow up procedure. At admission a detailed medical history including cardiovascular risk factors was taken from all patients. Neurological deficit was quantified according to the

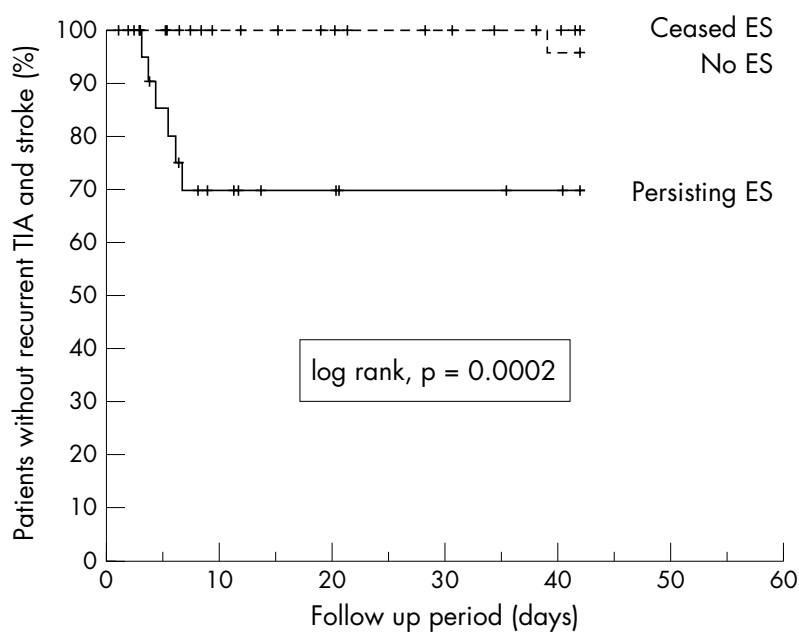

Figure 1 Kaplan-Meier survival curves comparing stroke and TIA free survival for persistence (continuous curve), cessation (broken curve), and initial absence (dotted curve) of embolic signals (ES) in patients with recent arterioembolic ischaemic event. Censored events include carotid endarterectomy, change of antithrombotic medication, and follow up examination after 4 to 6 weeks.

NIHSS score and was repeated after 24 hours and 4 days. Extracranial and intracranial vascular pathology was assessed by colour coded duplex sonography (SSH 380, Toshiba). Degree of extracranial carotid stenosis was classified as medium grade ( $\geqslant 50 \%$ local diameter reduction) at angle corrected peak systolic velocities $>120 \mathrm{~cm} / \mathrm{s}$, and as high grade 


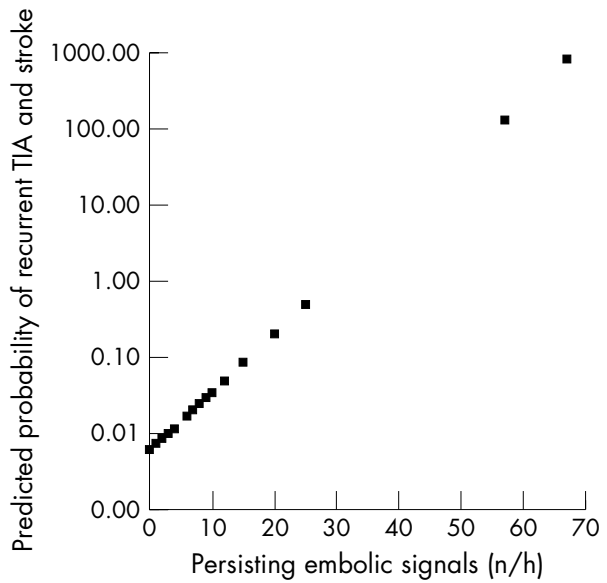

Figure 2 Predicted probability of recurrent TIA and stroke in relation to the number of persisting embolic signals as calculated by multivariate analysis.

( $\geqslant 80 \%$ local diameter reduction) at peak systolic velocities $>300 \mathrm{~cm} / \mathrm{s}$ or end diastolic velocities $>135 \mathrm{~cm} / \mathrm{s}^{10}$ Cut off values of angle corrected peak systolic velocities for the diagnosis of MCA stenosis were $155 \mathrm{~cm} / \mathrm{s}(<50 \%)$ and $220 \mathrm{~cm} / \mathrm{s}$ $(\geqslant 50 \%)$, respectively. ${ }^{11}$ Cerebrovascular reactivity was determined at the middle cerebral artery distal to the symptomatic stenosis by inhalation of a mixture of 5\% carbon dioxide and 95\% oxygen and subsequent hyperventilation to induce hypercapnia and hypocapnia. Brain CT or MRI was performed in all patients and was repeated after 24 to 48 hours if hemispheric signs persisted for more than 24 hours and initial scan failed to demonstrate a corresponding infarction. Holter monitoring and transoesophageal echocardiography (49 patients), both performed subsequently after admission according to clinical decision criteria, as well as a 12 lead ECG at admission showed no findings suggestive of cardioembolic stroke.

Also as part of the admission examinations, 1 hour bilateral simultaneous MCA monitoring with dual gated $2 \mathrm{MHz}$ pulsed wave probes (Multi-Dop X, DWL) was performed after informed consent. Periods of interest for embolic signals were assessed automatically, registered on line by the software (detection threshold of the relative intensity increase $\geqslant 12 \mathrm{~dB}$, calculated propagation distance 0.5 to $10 \mathrm{~mm}$ at a gate distance of $5 \mathrm{~mm}$ ), and stored on hard disk. Subsequent off line review by two independent observers blinded for patients and monitoring data included only events with unidirectional signal within the Doppler velocity spectrum (interobserver agreement $>99 \%$ ). Estimated sensitivity for artifact identification evaluated on $\sim 300$ produced artifacts in control subjects was $>98 \%$, ${ }^{12}$ estimated sensitivity for the detection of an embolic signal evaluated by reference DAT tape within the scope of a between centre comparison was $~ 95 \%$. Patients in whom embolic signals were detected distal to the symptomatic stenosis at the first monitoring underwent a second examination 1.8 days (mean) after secondary prevention had been initiated or modified. Device setting of the initial monitoring was maintained at follow up recording.

Antithrombotic prevention was decided on by the treating clinician without knowledge of the monitoring results and was started after the admission investigations. Sixty four of the 86 patients received an antiplatelet agent. In 31 without antithrombotic premedication, secondary prevention was started with acetylsalicylic acid (ASA) $(500 \mathrm{mg}$, continued at $300 \mathrm{mg} /$ day; $\mathrm{n}=24$ ), or, in cases of known gastric ulcer or allergy to ASA, ticlopidine ( $500 \mathrm{mg} /$ day; $\mathrm{n}=3$ ) or clopidogrel ( $75 \mathrm{mg} /$ day; $\mathrm{n}=4$ ). The last was used since it became available instead of ticlopidine and was started without a loading dose. In 33 patients with a pre-existing ASA medication (100 $\mathrm{mg}$ /day) already before ischaemia, ASA dosage was increased (500 mg, continued by $300 \mathrm{mg} / \mathrm{day} ; \mathrm{n}=23$ ) or replaced/ supplemented by ticlopidine $(n=3 / n=1)$ or clopidogrel $(n=1 /$ $\mathrm{n}=5$ ). Nineteen of the 86 patients initially received heparin, which increased mean activated partial thromboplastin time to 2.4 ((SD) 0.6) times the normal value. Twelve of these patients had no antithrombotic premedication. In seven patients who at the time of their ischaemic event already had received ASA (100 mg/day), this medication was stopped before anticoagulation in four but was continued in three

Recurrence of an ischaemic event during follow up was defined as the occurrence of neurological symptoms or clinical signs corresponding to the distribution area of the initially symptomatic stenosis that appeared after the initial deficit had completely resolved or a sudden deterioration of the initial or occurrence of new focal symptoms. All patients with a recurrent event subsequently underwent an additional CT or MRI, extracranial and intracranial duplex sonography, ECG, and routine laboratory evaluation, which were all required to be compatible with the diagnosis.

For the investigation presented here, follow up was terminated 6 weeks after admission. Outpatients without early endarterectomy or recurrent stroke are routinely re-evaluated at this time including recent medical history, neurological examination, and duplex sonography. The end point of follow up for stroke free survival analysis in the 86 patients was a recurrent ischemia in seven, carotid endarterectomy in 27, a change of antithrombotic medication in 10 , and censored follow up in 39. Three patients were lost to follow up.

All findings were documented in the local stroke data base, which covers all inpatients and outpatients with cerebrovascular diseases presented at the Department of Neurology. Results of TCD monitorings were stored separately and not referred to inpatients' medical records chart or disclosed to clinicians involved in the treatment of the patient.

Statistical analysis was performed using SPSS for Windows, Version 10.0. Frequency of clinical characteristics, embolic signals, and time periods were compared by $\mathrm{X}^{2}$ test, Fisher's exact test, and non-parametric tests for independent and related samples as appropriate. The relation between and adjusted relative risk of persistence of embolic signals and early ischaemic recurrence was analysed by Kaplan-Meier curves and estimated by Cox regression analysis. Significance was set at a $\mathrm{p}$ value of less than 0.05 .

\section{RESULTS}

At admission, embolic signals distal to the symptomatic stenosis were detected in 44 of the 86 patients. After initiation of an antithrombotic treatment, embolic signals persisted in 25 patients and had ceased in 19 by follow up monitoring. Patient groups did not differ by their baseline clinical characteristics, initial number of embolic signals, time between ischaemic event, antithrombotic prevention, and TCD monitoring (table 1). For calculation of recurrent stroke risk in relation to cessation or persistence of embolic signals, the 42 patients without signals at the initial monitoring served as controls. Mean time of follow up was 15.5 days in patients with persisting embolic signals, 35.2 in those in whom signals had ceased, and 32.2 in the control group. Six recurrent ischaemic events (two stroke, three TIA, one amaurosis fugax) occurred in the 25 patients with persisting embolic signals, all within 3 to 7 days after initiation of antithrombotic prevention ( 3 to 10 days after the initial ischaemic event). No event was seen in the 19 patients in whom signals had ceased. One patient of the control group had a recurrent TIA 39.1 days after the start of ASA (39.5 days after the initial event), l day before endarterectomy was scheduled. The persistence of embolic signals during secondary prevention was associated 
Table 3 Number of patients positive for embolic signals and number of signals before and after start of secondary prevention in relation to the administered antithrombotic agent

\begin{tabular}{|c|c|c|c|c|}
\hline & \multicolumn{4}{|c|}{ Secondary prevention initiated after 1st TCD monitoring } \\
\hline & \multicolumn{2}{|c|}{ Antiplatelet agent } & \multicolumn{2}{|c|}{ Intravenous heparin } \\
\hline & ES positive & $\begin{array}{l}\text { ES/hour Mean } \\
\text { (range) }\end{array}$ & ES positive & $\begin{array}{l}\text { ES/hour Mean } \\
\text { (range) }\end{array}$ \\
\hline \multicolumn{5}{|c|}{ No antithrombotic premedication: } \\
\hline 1 st TCD monitoring & 23 & $15.8(1-46)$ & 10 & $15.6(3-57)$ \\
\hline 2nd TCD monitoring & 10 & $3.3(1-6)$ & 10 & $15.3(3-67)$ \\
\hline \multicolumn{5}{|c|}{ Preexisting ASA, stopped after 1st TCD: } \\
\hline 1st TCD monitoring & & & 2 & $34.5(15-54)$ \\
\hline 2nd TCD monitoring & & & 2 & $38.5(20-57)$ \\
\hline \multicolumn{5}{|c|}{ Preexisting ASA, continued: } \\
\hline 1st TCD monitoring & 6 & $8.5(3-19)$ & 3 & $6.3(1-10)$ \\
\hline 2nd TCD monitoring & 0 * & & 3 & $7.7(1-5)$ \\
\hline
\end{tabular}

with an early recurrence of a TIA or stroke whereas their cessation within 4 days (mean 1.8 days) after the start of an antithrombotic therapy decreased this risk to a level as low as in patients without detectable signals at admission $(p=0.0002$, Kaplan-Meier survival analysis; fig 1). The incidence of a recurrent event was 0.45 per 30 patient-days if embolic signals persisted compared with 0.015 if signals could not be detected or had ceased. Persisting embolic signals remained a significant predictor of a recurrent event also after controlling for potential covariates (adjusted odds ratio 37.0; 95\% confidence interval $(95 \%$ CI) 3.5 to $333 ; \mathrm{p}<0.003)$ (table 2 ) with increasing risk with increasing signal frequency (adjusted odds ratio $1.2 ; 95 \%$ CI 1.1 to $1.4 ; \mathrm{p}<0.006$, fig 2 ).

Ten of 25 patients with persisting embolic signals and all 19 patients without signals at the second monitoring had received antiplatelet agents for secondary prevention, whereas heparin was administered to 15 with persisting and none without persisting signals $(p<0.001)$. In the six patients with recurrent events and persisting embolic signals, anticoagulation was performed in four (added on ASA in one) and was sufficient in three (activated partial thromboplastin time 1.8 to 2.0 of normal baseline values) but insufficient in one (1.1) at the time of the event. One patient had a TIA 4.1 days after the start of an ASA prevention, one an amaurosis fugax 4.9 days after clopidogrel.

The frequency and number of embolic signals before and after the start of a secondary prevention in relation to administered antithrombotic medication-that is, antiplatelet agents or intravenous heparin-are listed in table 3. In all 44 patients as well as in the subgroup of 33 without pre-existing antithrombotic medication, embolic signals had ceased in most patients under antiplatelet agents but persisted in all of those who were anticoagulated with heparin $(p<0.001)$. In patients with persisting embolic signals, their number had significantly decreased after antiplatelet agents but not after heparin. There was a trend to a higher rate of patients with cessation of embolic signals after the administration of ticlopidine/clopidogrel added on pre-existing ASA compared with ASA or ticlopidine/clopidogrel alone $(\mathrm{p}=0.068)$.

\section{DISCUSSION}

Our study provides evidence that a cessation of embolic signals found within 4 days after the start of an antithrombotic prevention, is associated with a risk reduction of a recurrent arterioembolic TIA or stroke within the next 6 weeks to a level as low as in patients without embolic signals after an initial recent ischaemic event. Patients in whom embolic signals persisted remained at high risk, which according to our investigation is estimated at almost 40 times the risk of patients in whom embolic signals could not be detected or had ceased. Embolic signals have been found to be a predictor of an early ischaemic recurrence in recent prospective studies on patients with symptomatic arterial stenosis with an adjusted relative risk about 10 times that of signal negative patients. ${ }^{12}$ By contrast with our study, these included patients with a wider time window since the index event, ${ }^{1}$ and with arterial lesions also in localisations other than the carotid or middle cerebral artery, ${ }^{2}$ and did not differentiate whether an antithrombotic medication had been altered after the TCD monitoring during follow up, probably not allowing direct comparison of risk estimations. However, as both studies only performed a single monitoring they did not yield data on the effect of a decrease of embolic signals on TIA and stroke risk.

Decrease and cessation of embolic signals in our patients were most likely caused by the administered antithrombotic agents. In consideration of the unknown spontaneous course of embolic signals in an individual patient, it has to be stressed that time intervals between both monitorings were short and did not differ in patients with and without embolic signals at the second monitoring. Further variables known or assumed to influence the prevalence of embolic signals-for example, degree and localisation of the stenosis, type of the initial ischaemic event, time since this event, and multiple recurring initial events ${ }^{3}{ }^{13-15}$ - also did not differ between the groups. Therefore, even considering that our patients were not randomised to the type of the antithrombotic prevention, our data strongly suggest that embolic signals are inhibited by antiplatelet agents rather than intravenous heparin. A failure of anticoagulation as well as the potential of antiplatelet agents to decrease embolic signals of arterial origin already has been suggested by previous case reports. In two patients with ongoing cerebral microembolism (and ischaemic events) during anticoagulation, replacement of warfarin/heparin by ASA/ticlopidine stopped both embolic signals and stroke recurrence. ${ }^{6}{ }^{16}$ Embolic signals detected in three patients with recently symptomatic atherosclerotic carotid stenosis persisted (as recurrent ischaemic events did in two) despite sufficient anticoagulation with intravenous heparin. ${ }^{5}{ }^{17}$ On the other hand, embolic signals significantly dropped in seven of nine patients (with four patients becoming signal negative) within 2 days after the start of a secondary prevention with ASA. ${ }^{12}$

With respect to selection criteria, sample size, and timing of the examinations, some reservations need to be made about the validity of our results. Differences between selected patients and those excluded relating to the frequency of multiple initial events and the presence of pre-existing antiplatelet medication might have biased selection to patients positive for embolic signals. ${ }^{3}$ However, as the primary intention of the 
study was to monitor the effect of an antithrombotic prevention on embolic signals and their relation to the risk of stroke recurrence, exclusion of patients with insufficient transtemporal bone window, other obstacles to TCD monitoring, and not determinable effects of recently started antithrombotic prevention on embolic signals was mandatory. As baseline characteristics did not differ between patients in whom embolic signals persisted and those signals had ceased (table 1) and Cox regression was used to correct prediction of ischaemic recurrence for baseline characteristics (table 2) this is not expected to alter the presented results. Although our study is one of the largest to have followed up patients with embolic signals after an ischaemic cerebrovascular event, the confidence interval of risk estimation is wide for the risk calculated for TIA and stroke. Confirmation of our results by a randomised to treatment study with higher patient numbers is required. The time of the second TCD monitoring was not prefixed in relation to the initial one or the start of antithrombotic prevention. This might be of minor relevance in patients who had received intravenous heparin and in whom monitoring was repeated when therapeutic anticoagulation has been reached as documented by an aPTT within the target range. In patients on antiplatelet agents, time of repeat TCD was chosen more arbitrarily. In previous follow up studies, reischaemia occurred within 2 to 25 days after the detection of embolic signals, ${ }^{12}$ and the maximal effect of ASA on embolic signals in responding patients has been shown to occur after $1-2$ days. ${ }^{12}$ Therefore, the 1-2 days was considered as an adequate target time period. At least in patients who had received ticlopidine or clopidogrel the effect on embolic signals still might be incomplete at this time. ${ }^{18}$ However, with respect to the early recurrence of symptoms in these patients an early effect of antithrombotic agents seems clinically relevant.

In summary, in patients in whom cerebral embolic signals distal to a recently symptomatic stenosis indicate an increased risk of recurrent TIA and stroke, cessation of these signals after the start of an antithrombotic prevention is associated with a substantial risk reduction. Early decrease of embolic signals in these patients with atherosclerotic arterial disease is seen after antiplatelet agents but not with intravenous heparin.

\section{Authors' affiliations}

M Goertler, T Blaser, S Krueger, K Hofmann, M Baeumer, C-W

Wallesch, Department of Neurology, University of Magdeburg,

Magdeburg, Germany

\section{REFERENCES}

1 Molloy J, Markus H. Asymptomatic embolization predicts stroke and TIA risk in patients with carotid artery stenosis. Stroke 1999;30:1440-3.

2 Valton L, Larrue V, le Traon A, et al. Microembolic signals and risk of early recurrence in patients with stroke or transient ischemic attack. Stroke 1998;29:2125-8.

3 Goertler M, Blaser T, Krueger S, et al. Acetylsalicylic acid and microembolic events detected by transcranial Doppler in symptomatic arterial stenoses. Cerebrovasc Dis 2001;11:324-9.

4 Behrens S, Daffertshofer M, Hennerici M. Stroke treatment guided by transcranial Doppler monitoring in a patient unresponsive to standard regimens. Cerebrovasc Dis 1999;9:175-7.

5 Georgiadis $\mathbf{D}$, Hill $M$, Zunker $P$, et al. Anticoagulation monitoring with transcranial Doppler. Lancet 1994;344:1373-4.

6 Markus H, Thomson N, Brown M. Asymptomatic cerebral embolic signals in symptomatic and asymtomatic carotid artery disease. Brain signals in symptomatic

7 Takada T, Akiyama H, Moriyasu H, et al. Disappearance of embolic signals on transcranial Doppler sonography following antiplatelet therapy in a patient with transient ischemic attacks. Rinsho Shinkeigaku 1998;38:329-33.

8 Ringelstein E, Sievers C, Ecker S, et al. Non-invasive assessment of $\mathrm{CO}_{2}$ induced cerebral vasomotor response in normal individuals and patients with internal carotid artery occlusions. Stroke 1988;19:963-9.

9 Widder B, Paulat K, Hackspacher J, et al. Transcranial Doppler $\mathrm{CO}_{2}$ test for the detection of hemodynamically critical carotid artery stenoses and occlusions. Eur Arch Psychiatr Neurol Sci 1986;236:162-8

10 de Bray J, Glatt B. Quantification of atheromatous stenosis in the extracranial internal carotid artery. Cerebrovasc Dis 1995;5:414-26.

11 Baumgartner RW, Mattle HP, Schroth G. Assessment of $\geqslant 50 \%$ and $<50 \%$ intracranial stenoses by transcranial color-coded duplex sonography. Stroke 1999;30:87-92.

12 Goertler M, Baeumer M, Kross R, et al. Rapid decline of cerebral microemboli from arterial origin after intravenous acetylsalicylic acid. Stroke 1999;30:66-9

13 Babikian V, Wijman C, Hyde C, et al. Cerebral microembolism and early recurrent cerebral or retinal ischemic events. Stroke 1997;28:1314-18.

14 Eicke $\mathbf{M}$, von Lorentz J, Paulus W. Embolus detection in different degrees of carotid disease. Neurol Res 1995;17:181-4.

15 Forteza A, Babikian V, Hyde C, et al. Effect of time and cerebrovascular symptoms on the prevalence of microembolic signals in patients with cervical carotid stenosis. Stroke 1996;27:687-90.

16 Segura T, Serena J, Molíns A, et al. Clusters of microembolic signals: a new form of cerebral microembolism presentation in a patient with middle cerebral artery stenosis. Stroke 1998;29:722-4.

17 Droste D, Ritter M, Kemeny V, et al. Microembolus detection at follow-up in 19 patients with acute stroke. Cerebrovasc Dis 2000;10:272-7.

18 Herbert J, Frehel D, Vallee E. Clopidogrel, a novel antiplatelet and antithrombotic agent. Cardiovasc Drug Rev 1993;11:180-98. 


\section{CORRESPONDENCE}

\section{Radiology of stroke}

The optimum time frame for imaging embolic infarcts for stigmata of haemorrhagic transformation should have merited discussion under the heading "special clinical circumstances", 1 not least because of conflicting evidence about the benefits versus risks of early anticoagulation in the context of unpredictable evolution of embolic infarcts with or without anticoagulant treatment. In a study comprising 30 patients with cardiogenic cerebral embolism, three patients with an initially non-haemorrhagic cerebral infarct, visualised by computed tomography within 12 hours of stroke onset, showed asymptomatic haemorrhagic transformation in the absence of anticoagulant treatment 2-8 days later. One other patient in this subgroup did, however, develop sudden worsening of hemiparesis despite having initially presented with a small infarct. ${ }^{2}$ Among 1457 patients anticoagulated with unfractionated heparin in the presence of embolic cerebral infarct associated with atrial fibrillation, haemorrhagic transformation (within 14 days) was significantly commoner $(\mathrm{p}<0.0001)$ than in their non-heparinised counterparts. ${ }^{3}$ Ischaemic stroke recurred with a $4.9 \%$ frequency in the latter subgroup (comprising 1612 patients) during that time frame, and this complication was significantly less common $(\mathrm{p}=0.001)$ in their anticoagulated counterparts. ${ }^{3}$ Anti-coagulation in the presence of haemorrhagic transformation has been advocated as being without risk on the basis of the outcome in 12 patients so treated ${ }^{4}$ but the caveat is that, in anothe study also involving patients with embolic stroke, the subsequent development of haemorrhagic transformation in 5 of 231 patients anticoagulated with heparin was associated with significant clinical deterioration..$^{5}$ It is this unpredictability in the consequences and tempo of haemorrhagic transformation and in the impact of early anticoagulation on this phenomenon that causes anxiety among clinicians at all levels of experience.

O M P Jolobe

Department of Adult Medicine, Tameside Genera Hospital, Fountain Street, Ashton-under-Lyne OL6 9RW, UK

\section{References}

1 Wardlaw JM. Radiology of stroke. J Neurol Neurosurg Psychiatry 2001;70/suppl 1):i7-11

2 Cerebral Embolism Study Group. Immediate anticoagulation of embolic stroke: brain hemorrhage and management options. Stroke 1984;15:779-89.

3 Saxena $\mathbf{R}$, Lewis $S$, Berge $E$, et al, for the International Stroke Trial Collaborative Group. Risk of early death and recurrent stroke and effect of heparin in 3169 patients with acute ischaemic stroke and atrial fibrillation in the international stroke trial. Stroke 2001;32:2333-7.

4 Pessin MS, Estol CJ, Lafranchise F, et al. Safety of anticoagulation after hemorrhagic infarction. Neurology 1993;43:1298-303.

5 Chamorro A, Vila N, Ascaso C, et al.

Heparin in acute stroke with atrial fibrillation: clinical relevance of very early treatment. Arch Neurol 1999;56:1098-102.

\section{Author's reply}

The strongest risk factor for haemorrhagic transformation of cerebral infarction in patients not treated with any antithrombotic or thrombolytic drug is simply having an extensive large infarct. It so happens that cardiogenic cerebral embolism often results in large cerebral infarcts (because thrombi arising from the heart are often large and block a largish vessel). Thus, there is an association between cardiogenic cerebral embolism and haemorrhagic transformation. This association may be exaggerated by administering antithrombotic or anticoagulant or thrombolytic therapy to these patients. Unfortunately, it is difficult to draw conclusions on the risks and benefits of anticoagulant treatment from non-randomised studies. The complete data from the international stroke trial (20000 patients) clearly show that heparin started within the first 48 hours of stroke and continued for the first 14 days may reduce the risk of recurrent ischaemic stroke but at the risk of increasing haemorrhagic stroke and death, and as a result there is no net benefit. ${ }^{1}$ When to start or continue anticoagulant treatment after stroke in the small proportion of patients with a clear cardiac source of embolism is a decision that needs to be made in light of each patient's risk factors and continues to be a thorny problem. However, the benefits of aspirin (while less effective) are still worthwhile with less risk of haemorrhagic transformation. There is no easy answer to this problem.

J M Wardlaw

Department of Clinical Nurosciences, Western General Hospital, Crewe Road, Edinburgh EH4 2XU, UK

\section{Reference}

1 International Stroke Trial Collaborative Group. The international stroke trial (IST): a randomised trial of aspirin, subcutaneous heparin, both, or neither among 19435 patients with acute ischaemic stroke. International Stroke Trial Collaborative Group. Lancet 1997;349:1569-81.

\section{Thunderclap headache, reversible cerebral arterial vasoconstriction, and unruptured aneurysms}

In his comprehensive review of thunderclap headache, ${ }^{1}$ Dr Dodick discusses two patients with the triad of thunderclap headache, cerebral arterial vasoconstriction, and unruptured cerebral aneurysms. We recently reported on two very similar patients, in whom the symptoms developed shortly after exposure to commonly used serotonin enhancing drugs. ${ }^{2}$ The interrelation between thunderclap headache, cerebral arterial vasoconstriction, and unruptured aneurysms is not clear, and in these four patients the aneurysms may well have been incidental findings. However, it is interesting that, in addition to segmental vasoconstriction, cerebral angiograms in patients with the Call-Fleming and some other vasoconstriction syndromes ${ }^{3}$ can have areas of vasodilatation beyond the normal diameter of the artery. Moreover, patients with stroke associated with the use of vasoconstrictive drugs such as cocaine and "ecstasy" are known to have an unusually high number of aneurysms. ${ }^{4}$ It is conceivable that patients who develop cerebral vasoconstriction or thunderclap headaches (without subarachnoid haemorrhage) are more likely to harbour aneurysms due to primary or drug induced abnormalities of vessel tone.

Dr Dodick reviews cases where thunderclap headache was associated with unruptured aneurysms, without cerebral arterial vasoconstriction, and where thunderclap headache was associated with vasoconstriction, without unruptured aneurysms. It should be noted that unruptured aneurysms have been associated with vasoconstriction, without thunderclap headache..$^{5}$ This point is emphasised by an additional, hitherto unpublished case (courtesy Dr C Miller Fisher) of severe cerebral vasoconstriction, stroke, and death associated with two unruptured and asymptomatic intracerebral aneurysms without thunderclap headache. The patient, a 65 year woman, was admitted in January 1977 with probable Guillain-Barré syndrome. The hospital course was notable for episodic hypertension (maximum blood pressure 200/ $100 \mathrm{~mm} \mathrm{Hg}$ ). On day 4, she developed cortical blindness, abulia, aphasia, and right hemiplegia. Computed tomography showed infarctions in both occipital lobes and a parasagittal meningioma. A selective cerebral arteriogram showed aneurysms in the anterior communicating and left middle cerebral artery, severe attenuation of proximal intracranial arteries, and "sausaging" of distal arteries. After returning from the arteriogram the patient became obtunded, then deteriorated clinically, and died on day 13. A necropsy showed cerebral oedema with bilateral temporal lobe herniations, infarctions in the inferior cerebellum and both occipital and frontal lobes, a parasagittal meningioma, and two unruptured aneurysms (a $5 \times 5 \mathrm{~mm}$ anterior communicating aneurysm and a $10 \times 7 \mathrm{~mm}$ left middle cerebral artery aneurysm). There was no evidence for arterial inflammation. Lymphocytic infiltration was present in the sciatic nerves, consistent with infectious polyneuritis. As stated in the review article, ${ }^{1}$ it is difficult to account for any mechanism whereby the aneurysms may have precipitated the vasoconstriction.

A B Singhal

Stroke Service, VBK-802, Massachusetts Generd Hospital, Boston, MA 02114 , USA; asinghal@partners.org

\section{References}

1 Dodick DW. Thunderclap headache. J Neurol Neurosurg Psychiatry 2002;72:6-1 1

2 Singhal AB, Caviness VS, Begleiter AF, et al. Cerebral vasoconstriction and stroke after use of serotonergic drugs. Neurology 2002;58:130-3

3 Singhal AB, Koroshetz W, Caplan LR Cerebral vasoconstriction syndromes. In: Bogousslavsky J, Caplan LR, eds. Uncommon causes of stroke. Cambridge: Cambridge University Press, 2001:114-23.

4 McEvoy AW, Kitchen ND, Thomas DGT. Intracerebral hemorrhage caused by drug abuse. Lancet 1998:351:1029.

5 Friedman P, Gass H, Magidson M. Vasospasm with an unruptured and unoperated aneurysm. Surg Neurol 1983;19:21-5.

\section{Author's reply}

I would like to thank Dr Singhal for his interest and thoughtful insights concerning the review article on thunderclap headache. ${ }^{1}$ I will address his comments in order. 
Firstly, I had already read with great interest the recent article from $\operatorname{Dr}$ Singhal et al regarding three patients with thunderclap headache, reversible vasospasm, and ischaemic stroke possibly secondary to exposure to serotonergic medications. He also correctly points out that the unruptured aneurysms found in some patients with thunderclap headache and reversible vasospasm are possibly incidental-a point that I made in the review article. On the basis of the association with unruptured aneurysms or exposure to sympathomimetic and serotonergic medications in some patients with thunderclap headache and vasospasm, he raises the provocative and interesting possibility that patients who develop thunderclap headache (without subarachnoid haemorrhage) are more likely to harbour aneurysms due to primary or drug induced abnormalities in vessel tone.

There are certainly cases of thunderclap headache with reversible vasospasm that have occurred shortly after exposure to sympathomimetic medications such as cocaine or amphetamines, as well as during hyperadrenergic metabolic states such as eclampsia and hypertensive crisis. ${ }^{3-6}$ Most of the patients described in the literature, however, did not harbour intracranial aneurysms, and prospective longitudinal studies of patients with nonaneurysmal thunderclap have not found an increased risk of subarachnoid haemorrhage. Ideally, a longer prospective study of patient with thunderclap headache with cerebrovas cular imaging or careful assessment of a large group of patients with unruptured aneurysms (such as the international unruptured aneuryms study) for a history of thunderclap headache would be required to address the hypothesis raised by Dr Singhal.

Dr Singhal also suggests that unruptured aneurysms may present with vasospasm in the absence of a thunderclap headache. The case (courtesy of C Miller Fisher) that he uses to illustrate this point is a very interesting one. While it is certainly possible that the unruptured aneurysms in this case may have given rise to the vasospasm, I believe the vasospasm in this 65 year old woman with Guillian-Barré syndrome was more likely related to the severe labile hypertension-a result of dysautonomia frequently seen in this disease. As alluded to earlier vasospasm has been well described in patient with acute hypertensive crises such as phaeochromocytoma, eclampsia, and hypertensive encephalopathy. Hypertensive encephalopathy with posterior leucoencephalopathy syndrome (PLES) was recently described in a patient with thunderclap headache, ${ }^{7}$ and I have just submitted a similar case for publication in a young woman who also had reversible vasospasm in the setting of a hypertensive crisis and PLES. In fact, it is possible that in many cases of drug induced cerebral vasospasm, the effect on vascular tone and calibre may reflect the effect of these sympathomimetic drugs on arterial blood pressure in addition to a direct vasoconstrictive effect of the drugs. Indeed, it would have been of notable interest to know the arterial blood pressure in the patients he described with reversible vasospasm and stroke in patients exposed to serotonergic medications, since the magnetic resonance imag ing abnormalities in his patients are very similar to the changes seen in patients with PLES.

D W Dodick

Department of Neurology, Mayo Clinic Scottsdale,

13400 East Shea Boulevard, Scottsdale, Arizon 85259, USA; dodick.david@mayo.edu

\section{References}

1 Dodick DW. Thunderclap headache. J Neurol Neurosurg Psychiatry 2002;72:6-11.

2 Singhal AB, Caviness VS, Begleiter AF, et al. Cerebral vasoconstriction and stroke after use of serotonergic drugs. Neurology 2002;58:130-3.
3 Armstrong FS, Hayes GJ. Segmental cerebral arterial constriction associated with pheochromocytoma. J Neurosurg $1961 ; 18: 843-6$.

4 Trommer BL, Homer D, Mikhael MA. Cerebral vasospasm and eclampsia. Stroke 1988; 19:326-9.

5 Margolis MT, Newton TH. Methamphetamine ("speed") arteritis. Neuroradiology 1971;2:179-82.

6 Kaye BR, Fainstat $\mathrm{H}$. Cerebral vasculitis associated with cocaine abuse. JAMA 1984;258:2104-6.

7 Tang-Wai DF, Phan TG, Wijdicks EFM. Hypertensive encephalopathy presenting with thunderclap headache. Headache 2001;41:198-200.

\section{Cochlear implantation in a profoundly deaf patient with MELAS syndrome}

In response to the article "Cochlear implantation in a profoundly deaf patient with MELAS syndrome" (mitochondrial myopathy, encephalopathy, lactic acidosis, and stroke-like episodes), ${ }^{1}$ we feel concerned that this patient may have a different diagnosis. This woman who received a cochlear implant is described as having the MELAS syndrome, in both the title and the text, when perhaps she has the less severe maternally inherited diabetes mellitus with deafness (MIDD) syndrome.

She has the A3243G point mitochondrial DNA (mtDNA) mutation associated with insulin dependent diabetes mellitus, congenital cataracts, short stature, leg weakness, fatigue, and sensorineural hearing loss (SNHL), with no encephalopathy or strokes. The age of onset of SNHL was 22 years, with a slow deterioration to right profound SNHL at the age of 29 years, and bilateral profound SNHL and tinnitus at the age of 30 years Caloric testing and computed tomography of her temporal bones were both normal. Her mother suffered from diabetes, glaucoma, and a lesser degree of SNHL, and a sister has profound SNHL and mental retardation.

MELAS is a multisystem disorder with a wide variety of possible clinical features. Among these multiple features, the diagnostic criteria for MELAS are as follows ${ }^{2}$.

- Stroke-like episodes before age 40 years;

- Encephalopathy (seizures, dementia, or both);

- Mitochondrial myopathy (lactic acidosis, ragged red muscle fibres, or both):

- Two of the following three: normal early psychomotor development, recurrent headache, recurrent vomiting.

Now these clinical findings can be confirmed with a positive molecular genetic test for mtDNA mutations. ${ }^{3}$ The A3243G mutation in the mitochondrial tRNA ${ }^{\text {Leu(UUR) }}$ gene, MTTLl, causes MELAS and is responsible for MELAS in approximately $80 \%$ of patients.

MIDD has a narrower phenotype of bilateral, progressive, symmetrical SNHL, generally preceding diabetes mellitus (ranging from abnormal glucose tolerance to insulin dependent diabetes mellitus) and occurs in adulthood, on a background of maternal inheritance. Sporadic occurrence has been noted. ${ }^{4}$ It is associated with short stature and can be expressed as type 1-like or type 2-like diabetes. $^{5}$ The A3243G transition mutation has been identified as the cause of MIDD in $60 \%$ of cases.

In patients with mtDNA disease, affected cells and tissues tend to harbour mixtures of mutant and wildtype mtDNA in different proportions. This is called "heteroplasmy", as opposed to "homoplasmy", where only one type is present. It is hypothesised that phenotypic expression of mtDNA pathology may occur when heteroplasmy within an organ reaches a certain level. This concept is known as the "threshold effect". The severity of the phenotype is thought to correlate with the degree of heteroplasmy in different tissues. Interestingly, both syndromes, MELAS and MIDD, can be found in a single pedigree with the A3243G mutation. The A3243G mutation is also associated with Kearns-Sayre syndrome. Assuming that all patients with the A3243G mutation have the MELAS syndrome leads to an incorrect diagnosis, with significant implications for patient counselling. A diagnosis of MELAS implies that the patient has developed stroke-like episodes or encephalopathy.

As more people with SNHL become genotyped and the identification of the true prevalence of mitochondrial SNHL becomes more obvious, a database of already successfully treated patients by cochlear implantation will be useful for quantitative analyses of performances of these patients with cochlear implants. Here also, the correct label must be assigned to patients.

More information on mitochondrial SNHL can be obtained on the Hereditary Hearing loss Homepage on http://www.uia.ac.be/ dnalab/hhh/.

A R Sinnathuray, V Raut, J G Toner Department of Otolaryngology, Belfast City Hospital, Belfast, UK

A Magee

Department of Medical Genetics, Queen's University, Belfast at the Belfast City Hospital

Correspondence to: Mr J G Toner, Director, Regional Cochlear Implant Centre, Belfast City Hospital, Lisburn Road, Belfast BT9 7AB, Northern Ireland, UK; jgtoner@ntlworld.com

\section{References}

1 Hill D, Wintersgill S, Stott L, et al. Cochlear implantation in a profoundly deaf patient with MELAS syndrome. J Neurol Neurosurg Psychiatry 2001;71:281.

2 Hirano M, Ricci E, Koenigsberger MR, et al. Melas: an original case and clinical criteria for diagnosis. Neuromuscul Disord 1992;2: 125-35.

3 DiMauro S. MELAS (mitochondrial encephalomyopathy, lactic acidosis, and stroke-like episodes; myopathy, mitochondrial-encephalopathy-lactic acidosis-stroke). In: GeneReviews at GeneTests-Gene Clinics: Medical Genetics Information Resource [database online]. Copyright, University of Washington, Seattle. 1997-2001. 26 February 2001

http://www.genetests.org.

4 Oshima T, Ueda N, lkeda K, et al. Bilateral sensorineural hearing loss associated with the point mutation in mitochondrial genome. Laryngoscope 1996;106:43-8.

5 Remes AM, Majamaa K, Herva R, et al. Adult-onset diabetes mellitus and neurosensory hearing loss in maternal relatives of MELAS patients in a family with the tRNA(Leu(UUR) mutation. Neurology 1993;43:1015-20.

\section{Author's reply}

We are grateful to Dr Sinnathuray and colleagues for their very useful comments on the precise diagnosis of our patient's condition. We agree entirely with the comment that the A3243G mutation also occurs in maternally inherited diabetes mellitus with deafness (MIDD). In our patient the original diagnosis was made by a clinical geneticist in 1994 and therefore, in a rapidly changing field, 
greater precision in diagnosis might have been possible with a further genetics consultation at a later date. We should point out that this article was originally submitted in November 2000 and this, also, may have contributed to the diagnosis of MELAS syndrome rather than MIDD syndrome. We are most grateful to Dr Sinnathuray and colleagues for their useful comments.

J Graham

UCL Cochlear Implant Unit, Royal National Throat Nose \& Ear Hospital, 330-332 Gray's Inn Road London WCIX 8DA, UK

\section{Bilateral lesions restricted to the posteroventral pallidum are unlikely to provoke corticobulbar syndrome and psychic akinesia}

Merello et al reported a randomised study comparing bilateral simultaneous posteroventral pallidotomy (PVP) with a combination of unilateral PVP and contralateral pallidal stimulation. ${ }^{1}$ After having included three patients in each group, the study had to be aborted because of the severe complication encountered in the patients who had had bilateral pallidotomy.

This interesting paper raises some serious concerns.

First, the three patients who had bilatera PVP had a mean age of 67 years and those who had PVP and contralateral pallida stimulation had a mean age of 55 years. This difference in age is said to be non-significant. As there are only three patients in each group it would perhaps have been more appropriate to have given the ages of the individual patients rather than the means.

Second, at three months after surgery, the patients who had bilateral PVP showed deterioration in parts I (mood) and II (activity of daily living) of the unified Parkinson's disease rating scale (UPDRS). The subscores of gai and postural instability worsened significantly. The patients showed deterioration in depression and apathy scores, and it was not possible to perform neuropsychological evaluation after surgery. The patients required feeding tube, their gait freezing deteriorated, and they had no benefit from increased levodopa doses. They suffered from severe loss of initiative and motivation. In my opinion, even though bilateral pallidotomy may increase the risks of complications, ${ }^{2-5}$ the disastrous outcome of the three patients described in Merel lo's paper poses serious questions as to the exact location of the lesions. I believe that in order to provoke the severe corticobulbar syndrome and "psychic akinesia" described, the pallidal lesions must have encroached on the internal capsule bilaterally, and also have included antero-dorso-medial parts of the GPi.

The authors wrote that "brain MRI three months after surgery showed that all nine lesions and the three electrodes were located entirely within the GPi. Coordinates of the lesion/lead as well as lesion volumes were no significantly different between the groups." The authors concluded: "Our present findings argue against the possibility that lesion inaccuracy is responsible for the unacceptable rate of side effects of bilateral procedures as targets were confirmed by microrecording, lesions checked by MRI and the same criteria were followed either for lesioned or stimulated patients."

It is indeed very fortunate that the authors did perform the postoperative MRI at three months after surgery-that is, when the surgical oedema that would disturb the interpretation of the lesion location had completely resolved. From a didactic point of view, and to allow the reader to learn more about the anatomical substrate of this rather catastrophic outcome in patients with bilateral PVP, the MRI scans should have been shown in this important paper. I invite Merello et al to publish relevant axial and coronal postoperative brain MRI scans of these three patients in their answer to this letter, showing the locations of the bilateral posteroventral GPi lesions that were responsible for the reported "corticobulbar syndrome and psychic akinesia."

M I Hariz

Department of Neurosurgery, University Hospital, 90185 Umeå, Sweden; marwan.hariz@neuro.umu.se

\section{References}

1 Merello M, Starkstein S, Nouzeilles Ml, et al. Bilateral pallidotomy for treatment of

Parkinson's disease induced corticobulbar syndrome and psychic akinesia avoidable by globus pallidus lesion combined with

contralateral stimulation. J Neurol Neurosurg Psychiatry 2001:71:611-14.

2 Scott R, Gregory R, Hines N, et al. Neuropsychological, neurological and functional outcome following pallidotomy for Parkinson's disease. A consecutive series of eight simultaneous bilateral and twelve unilateral procedures. Brain 1998; 121:659-75

3 Schuurman PR, de Bie RM, Speelman JD, et al. Bilateral posteroventral pallidotomy in advanced Parkinson's disease in three patients. Move Disord 1997; 12:752-5.

4 Counihan TJ, Shinobu LA, Eskandar EN, et al. Outcomes following staged bilateral pallidotomy in advanced Parkinson's disease. Neurology 2001;56:799-802.

5 Intemann PM, Masterman D, Subramanian I, et al. Staged bilateral pallidotomy for reatment of Parkinson disease. J Neurosurg 2001;94:437-44.

\section{Author's reply}

We greatly appreciate the publication of the letter from Professor Hariz, which gives us occasion to provide more information about our paper and confirm the dangerous effect of simultaneous bilateral lesions within the GPi. We all know how limited the literature is on negative results of surgical procedures and how important they are. Surgery for Parkinson's disease is an extremely useful tool in a certain subgroups of patients, but it is not entirely risk-free and unfortunately many of the side effects seen at the bedside are poorly represented in published reports.

On the basis of unpublished descriptions by many neurosurgeons, bilateral procedures are performed by placing a normal lesion on one side, involving as much as possible of the motor portion of the GPi, followed by a smaller contralateral lesion. An excellent point arises from the concern expressed by Hariz: should both lesions be the same size? Perhaps staged asymmetric lesions could provide an alternative, but this was not the case in our report; we made simultaneous lesions which both involved as much as possible of the motor portion of the GPi, and our conclusions should not be extended to other surgical contexts

As requested, we provide MRIs of our cases (fig 1) and fully agree that lesion placement is crucial, as Hariz is well aware, given his reported outcome of five of 13 patients (that is, almost $40 \%$ ) who subsequently required seven further procedures, presumably because of initial lesion misplacement. ${ }^{1}$ Whatever the importance of descriptive photography, we believe it was more important that non-significant statistical differences were found in lesion/stimulation placement between the groups, and clinical psychic
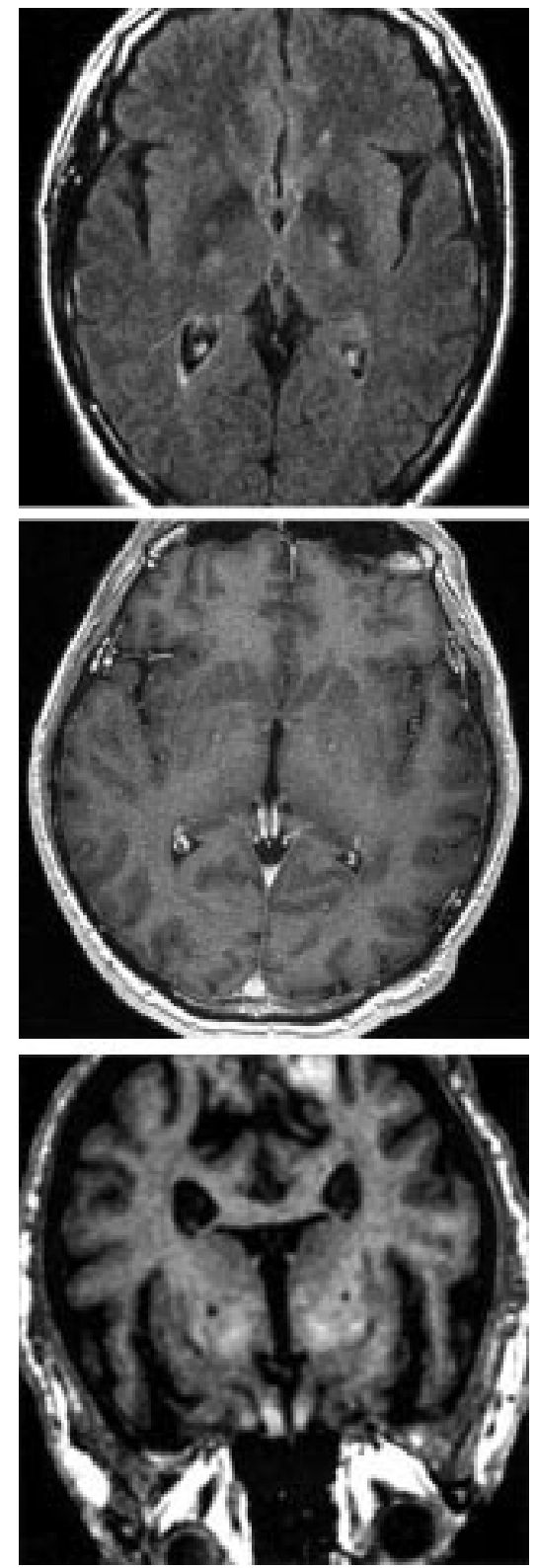

Figure 1 Axial MRI scans with three month old bilateral pallidal lesion performed in the patients who underwent bilateral ablative procedures.

akinesia was only present in simultaneous bilaterally lesioned cases.

We are sure that Hariz must have already read a recent review by Laplane and Dubois, which clearly describes the psychic akinesia syndrome as a result of bilateral basal ganglia lesions, providing deep insight into the non-motor roles of the basal ganglia, such as behavioural activation, cognitive processing, affectivity, and conscious awareness, with which we fully agree.

M Merello

Movement Disorders Section, Raul Carrea Institute for Neurological Research, FLENI, Buenos Aires,

$$
\text { Argentina; }
$$

mmerello@fleni.org.ar

\section{References}

1 Hariz M, Bergenheim T. A 10-years follow-up review of patients who underwent Laksell's posteroventral pallidotomy for Parkinson's disease. J Neurosurg 2001;95:552-8. 
2 Laplane D, Dubois B. Auto-activation deficit: a basal ganglia related syndrome. Move Disord 2001;16:810-14.

\section{BOOK REVIEWS}

\section{Ischemic cerebrovascular} disease

By Harold P Adams, Vladimir Hachinski, and John W Norris (Pp 575, £95.00). Published by Oxford University Press, New York, 2001. ISBN 01951-328-90

The most recent book in the very successful "black book" Contemporary neurology series from Oxford University Press is a monograph on brain ischaemia. The book is written by three experienced and well respected North American authors-Adams from the United States and Hachinski and Norris from Canada. The present monograph is a successor to previous book entitled The acute stroke by Hachinski and Norris published 16 years ago

There are now many books on stroke and on brain ischaemia. While reading this present endeavour, I continued to ponder the role of this monograph among the already burgeoning library of books. Whom is it aimed at? Who will profit most by its content? When, why, and how will readers use this book?

The text can be conveniently divided into four parts. The initial portion consists of fou chapters: an introductory general chapter followed by single survey chapters on epidemiology, clinical presentation of ischaemic and transient ischaemic strokes, and imaging and laboratory evaluation of these patients. The second portion of the book consists of five descriptive chapters: four concern differen stroke aetiologies-atherosclerotic diseases, non-atherosclerotic vasculopathies, cardiac sources of embolism, and prothrombotic states; the fifth chapter considers ischaemic strokes in the young. The final five chapter discuss management: medical therapy, surgical therapy, acute management of patient with ischaemic stroke, and hospital management and rehabilitation. The managemen section, although consisting of only five chap ters, makes up 245 pages, nearly half of the 575 pages of the book

The book has some attractive features that make it very user friendly. It is well organised. There is a detailed outline at the beginning of the book and at the beginning of each chapter. Furthermore, there are clear bold subhead ings and a detailed index. These feature make it quite easy to locate desired information. Tables are sprinkled amply through out and the tables succinctly summarise key points. The book is very heavily referenced and the references are up to date. There are ample figures that illustrate well the main disorders and the main diagnostic tools. A unique feature is the inclusion of clear diagrams and figures of echocardiograms Cardiac investigations are not usually covered nearly as well in monographs about stroke.

The best and most useful portion of the book is the section on management of patients with ischaemic stroke. This was the core of the predecessor of this book. Treatmen discussions are practical, detailed, evidence based, and up to date. The chapter on management of patients with acute ischaemic stroke is especially well done and will be quite useful for non-neurologists and non-stroke neurologists who lead stroke treatment in hospitals and stroke units. The chapters on clinical presentation and stroke aetiologies are less successful. Except for coverage of cardiac investigations and prothrombotic states, these chapters are rather brief and general, and serve only as introductions to the subjects discussed. In the non-management chapters, the authors seek to cover the waterfront and at least mention most things neophytes and non-stroke experts would want to look up. These non-management chapters are covered much better and in much more detail in other texts. The presentations are practical and are time locked to trials and results of treatment. There is little theoretical background or detailed discussions of anatomy, pathology, and pathophysiology. The attempt to cover all topics means that some are very scantily considered. The sections on vertebral artery disease, cerebellar infarction, and lacunar infarction are extremely brief. Many of the nonatherosclerotic conditions and cardioembolic sources are mentioned only in brief pithy paragraphs. Non-stroke experts would derive the barest information from the text but can look up references. Unfortunately, most references are only to journal articles; references to monographs and review of topics considered scantily would also have been helpful.

This book will be most useful to nonneurologists and non-stroke specialists who have the responsibility of managing patients with acute brain ischaemia acutely in emergency rooms and in hospitals. It serves as an excellent reference source concerning a wide variety of topics related to brain ischaemia which are considered in more detail elsewhere.

Louis Caplan

\section{The behavioral neurology of white matter}

Edited by Christopher M Filley (Pp 267, $£ 43.50$ ). Published by Oxford University Press, New York, 2001. ISBN 0-19-513561-X

This is a single author review and is a small book of 279 pages. It is divided into three parts, the first covering the normal function, development, and imaging of white matter. The second and largest covers diseases affecting white matter. While the range of conditions covered is comprehensive, each condition receives from a short paragraph to a couple of pages. While the material in the first two sections therefore focuses on white matter, these sections do not provide any information that would not be readily accessible in standard neurological texts. The third section deals specifically with the cognitive and neurobehavioural aspects of white matter disease. An overview of the cognitive changes that may be seen is provided along with further discussion of individual syndromes but again the information provided on each syndrome is brief. Similar comments apply to the following section on psychiatric syndromes. Readers consulting the book for advice on any aspect of management will be disappointed; this is scarcely mentioned at all Another common issue, the selection of appropriate scales and tests for the assessment of cognitive loss, is also striking by its absence.

It is difficult to see where this book will fit in; the first two sections would be better covered elsewhere. The final section provides more unusual material but even so this is brief, somewhat theoretical, and devoid of information on diagnosis or management. It may be useful as an introductory monograph for people in training entering the field.

John Bowler

\section{Channelopathies of the nervous system}

Edited by M R Rose and RC Griggs (Pp 347 $£ 60.00)$. Published by Butterworth Heine mann, Oxford, 2001. ISBN 0-7506-4507-5

Over the past few years there has been an explosion of knowledge regarding a group of diseases that have become known as the channelopathies. Like many new chapters of medical discovery it always seems obvious in retrospect. After all, ion channels are one of the most critical structures for normal neural activity. This cascade of new knowledge has now firmly established that dysfunction of both ligand gated and voltage gated ion channels may cause human diseases. The dysfunction either may be caused by autoimmune attack, such as myasthenia gravis, or may be the result of mutations in ion channel genes, such as the skeletal muscle channelopathies. In the main, channelopathies are disorders of excitable tissues and the nervous system is of course particularly affected.

It is therefore timely that Channelopathies of the nervous system should be published to provide a snap shot of current knowledge in this area. The editors state that their aim is "to inform both clinicians and neuroscientists as to the state of the art of neurological channelopathies, both clinically and scientifically". I think this has been achieved through the contributions of 34 recognized authorities in various subfields of neurological channelopathies.

The foreword is particularly informative and sets the scene very well for what is to follow. In the preface the editors acknowledge that the ultimate importance of channelopathies and of ion channel dysfunction remains to be determined. It is certainly true that all the channelopathies defined to date are relatively rare diseases. However, there is of course enormous expectation that ion channel dysfunction will be important in the most common paroxysmal disorders: epilepsy and migraine. This remains unproved.

The layout of the book is logical and generally user friendly. Each chapter stands more or less alone and as expected for a multiauthor text the styles vary. The book is divided into eight main parts: basic science, assessment of channel function (in vitro and in vivo) channel gene expression, genetic and acquired neuromuscular channel disorders, centra nervous system disorders, toxin induced channel disorders, and potential channel disorders. Recent genetic discoveries indicate that proximal myotonic myopathy and Schwartz-Jampe have in fact both bitten the dust as potential channelopathies! I found the chapters on the central nervous system disorders especially readable although already out of date in what is such a rapidly expanding area.

This is one of the first texts on this subject and I can recommend it to interested neurologists and neuroscientists.

Michael Hanna

\section{Disorders of voluntary muscle, 7th edn}

Edited by G Karpati, D Hilton-Jones, and R C Griggs (Pp 775, £140.00). Published by Cambridge University Press, Cambridge, 2001. ISBN 0-521-65062-3

It is estimated that at least one in 500 people will be affected by specific genetic or other lifelong neuromuscular disorders. Inevitably 
this figure is likely to be a significant underestimate because of inadequate case ascertainment, as well as our limited ability to identify what is likely to be another large number of as yet unrecognised muscle disorders. Into the latter group may fall patients who complain of muscle weakness, fatigue, or aching in whom no specific abnormality can yet be identified. Thus, muscle diseases constitute an important area of clinical activity and such patients are seen by neurologists, rheumatologists, general physicians, and a variety of other specialists. Thus, an up to date, comprehensive, and accessible textbook is extremely valuable for the generalist, as well as for those with a specific interest in muscle disorders.

This book has become a standard text for myologists and neurologists alike ever since its first publication in 1964. It has been through several editions and this most recent one has been supervised by three leading myologists. It is divided into four sections covering the scientific basis of muscle disease, methods of investigation, clinical features of muscle disorders, and, finally, the principles for their management. This therefore provides a comprehensive review of the foundations of neuromuscular diseases. The list of contributing authors is impressive. There are several outstanding contributions. I will mention only a few of these.

Skeletal muscle biochemistry is often an area where even myologists begin to feel uncertain. There have been several important recent advances in this area, particularly in understanding the relation between biochemical defects and clinical manifestations. The section on skeletal muscle biochemistry by John Land is exceptional and provides a clear and succinct view of the important areas of skeletal muscle chemistry, including the effects of exercise and training. This section complements the chapter on metabolic myopathies, which provides a detailed account of muscle biochemistry and how it may result in human disease. Inevitably some of the sections are brief but this is balanced by a good range of references. The two sections taken together should prove a significant help to those having to deal with patients who present with metabolic abnormalities of muscle.

The morphological examination of muscle disease lies at the centre of the evaluation of patients with myopathies. The section by Sewry and Dubowitz provides an excellent background review of this area, as well as a comprehensive analysis of morphological abnormalities in muscle disease. Inevitably the contribution has had to be condensed but this section should provide a rapid and easy guide to those who may not necessarily be experts in muscle morphology.

The clinical evaluation of the patient with symptoms of muscle disease is critical to achieving an accurate diagnosis. Generally, diseases of muscle have only a limited range of clinical expression and it is often the subtle features that give a guide to diagnosis or an appropriate plan of investigation. Muscle pain is probably one of the most frequent complaints and, as intimated above, investigation of many of these patients is negative, although this does not, of course, exclude their having an underlying muscle disorder. A careful approach to patients with myalgia is critical. Thus, it is helpful for this topic to have been covered in some detail in this section. Moreover, the painful muscle syndromes are specifically covered by Lane, and this detailed analysis of the various causes of this symptom is also particularly helpful.
Several of the dystrophies, congenital myopathies, and, of course, the inflammatory myopathies are covered in some detail, each in separate sections. These are, generally speaking, up to date and provide, in particular, a good account of the recent advances in the molecular genetics, particularly of the dystrophies. The section on mitochondrial disorders is also comprehensive and provides a useful algorithm for assessment of patients with possible mitochondrial disease. It is the section on the inflammatory myopathies that will probably be most used by generalists, including both neurologists and rheumatologists. The section written by Dalakas and Karpati is excellent and provides a comprehensive overview of the clinical, morphological, aetiological, and therapeutic aspects of these disorders. In particular, the discussion of the involvement of muscle in other inflammatory disorders is helpful. My only suggestion might have been an algorithm to help guide clinicians in the treatment of these disorders.

Genetic counselling in muscle diseases has now become a critically important area Therefore, the chapter by Bushby is very welcome. This sets out clearly the approach that clinicians should take to achieving a diagnosis and to counselling patients and relatives with the various types of inherited muscle disease. I imagine that this section in particular will find its way in some easily accessible form into the clinic drawer.

Finally, the last chapter deals with practical management issues in patients with muscle disease. This is clearly a very important area for patients who sadly often progress inexorably and require an increasing degree of help from carers and the medical profession as each year passes. This is one of the most important areas for managing patients with muscle disease and it is pleasing that this has been covered in some detail.

Where do the faults lie? In reality, none of my criticisms are anything but quibbles. Some of the sections seem a little superficial but inevitably this must reflect the constraint of chapter size in what must be intended to be a single volume text. There are of course other texts with which this will have to compete. Both Myology by Engel and Franzini-Armstrong and Neuromuscular disorders by Katirji et al are also excellent texts covering a similar range of topics. Needless to say, these are all pretty hefty tomes and the reader will have to select which of these suits him or her best. The latest Disorders of voluntary muscle must rank alongside the other top texts in this area.

Anthony Schapira

\section{Clinical guidelines in old age psychiatry}

By A Burns, T Dening, and B Lawlor (Pp 208, $£ 29.95)$. Published by Martin Dunitz, London, 2002. ISBN 1-84184-0297

Do we really need a book on clinical guidelines for old age psychiatry? Read this book and think you will agree with me the answer is yes! I suspect many clinicians, like myself, have an innate dislike of guidelines. They are perceived as constraining clinical freedom, are generally (inevitably) reductionist in their approach, and may be used as a stick with which to beat us. Furthermore, the provenance of some guidelines is dubious but once published they garner a mantle of authority that is difficult to neutralise.

This excellent book summarises 129 guidelines, statements, official reports, and policy documents on an enormous variety of issues including diagnostic criteria and treatment of most disorders an old age psychiatrist is likely to encounter, service standards, and legal and ethical issues. Some of the more interesting, and important, areas are genetic testing for Alzheimer's disease, advice on capacity and decision making, electronic tagging, advice on bathing persons with dementia, and use of music therapy. Many governmental publications are summarised into a page or so, including "Forget-me-not", the National Service framework for older people, "No secrets", "The way to go home", "The coming of age", and other essential reading. I also recommend the introduction, which has a balanced overview about how guidelines are constructed, their use, and their shortcomings (including legal issues). If I have one suggestion for the second edition, it is that there be a brief critical appraisal of each guideline, although the authors do provide a template for the reader to do this.

The same stable have produced another excellent compendium, Assessment scales in old age psychiatry by Burns et al (1999), that must have saved countless hours of researchers' time and is in my view an essential companion to anyone undertaking research in the discipline. Clinical guidelines in old age psychiatry has a broader audience and is likely to prove just as valuable.

James Warner

\section{Mood and anxiety disorders in children and adolescents: a psychopharmacological approach}

By David Nutt, Caroline Bell, Christine Masterson, and Clare Short (Pp 110, $£$ 19.95). Published by Martin Dunitz Publishers, London, 2001. ISBN 1-85317-924-8

Anxiety disorders are among the more common psychiatric disorders of childhood, and adolescent depression is being increasingly recognised in clinical practice. In contrast with the popularity of psychotropic medication in the treatment of adults with anxiety and depressive disorders, it is comparatively rare for this to be prescribed in childhood. This is partly because of the efficacy of alternative psychotherapeutic techniques but is also determined by the paucity of supportive research for psychotropic drugs until recently.

This is now changing rapidly and evidence is emerging for the efficacy of selective serotonin reuptake inhibitors for both anxiety and depressive disorders of childhood.

This book is timely in outlining the current state of knowledge on these disorders from a psychopharmacological perspective and in aiming to give clinicians practical advice on the use of medication in this age group. It draws on knowledge-mainly from the adult literature-on underlying neurobiological processes. It gives an overview of neurotransmitters involved, the mechanisms of action, and side effect profiles of various drugs available. The research evidence is reviewed and practical advice is given on the use of medication. Families are becoming better informed about different child psychiatric treatments and they may be expected to be offered treatment choices and their evidence base. This book will be helpful to clinicians when considering the indications and contraindications of medication as part of clinical interventions.

Elena Garralda 


\section{Neurological eponyms}

Edited by Peter J Koehler, George W Bruyn, and John M S Pearce (Pp 386, £39.50). Published by Oxford University Press, New York, 2000. ISBN 0-19-513366-8

I enjoyed this book. It is one to delve into rather than to read formally. It appears to have had a rather long gestation since the introduction is dated September 1999. The book is separated into five sections though at times the inclusion of a particular chapter in a particular section seems somewhat arbitrary. The editors have aimed for a uniformity of approach in which a brief historical survey is followed by a resume of the original description and then a setting of that description in a modern context. Inevitably the quality and interest of the contributions vary considerably. The chapters are well illustrated with both portraits of the person and, where relevant, illustrations from original descriptions. In general the editing has been thorough though curiously the chapter on Creutzfeldt-Jakob disease ends with a paragraph covering data that had been previously discussed in the middle of the text. Some authors chose not to question the appropriateness of the attribution of a particular syndrome or sign to a particular person; others do so sometimes amusingly as, for example, in the chapter by Bruyn and William Gooddy on Horner's syndrome. There is little to quibble with in terms of the attributions, though why on earth cluster headache is entitled Horton's syndrome is not entirely clear to this reviewer. Although Horton himself had the temerity to suggest that the specific type of headache he described in 1939 had not been described adequately in the literature, he clearly had not read Wilfred Harris's contributions published in Neuritis and neuralgia in 1926 and later in The facial neuralgias in 1937. Harris described virtually all the characteristic features of cluster headache including distribution, periodicity, duration, frequency, presence of conjunctival injection and lacrimation, the sometimes associated Horner's syndrome, and the response to subcutaneous ergotamine. So much for a headache that had not been described adequately in the literature.

My only concern about this book is that the publishers, who seem now to be publishing as frequently from New York as from Oxford, seem to have acquired a taste for American spelling. Perhaps they need a visit down the road at Oxford to the OED.

David Perkin

\section{Arachnoiditis: the silent epidemic}

Edited by J Antonio Aldrete (Pp 339, US\$ 1 10.00). Published by Futuremed Publishers, Denver, and the Arachnoiditis Foundation Inc, Seaside, 2000. ISBN 968-7860-56-1

This book provides a comprehensive analysis, and comments on a condition we hope will be significantly reduced in incidence with new imaging modalities. It provides an extensive bibliography providing reference on the views expressed, the likely multifactorial aetiological factors responsible for the development of a very disabling combination of signs and symptoms, and management strategies. The earlier chapters provide a historical perspective together with relevant anatomical, pathological, and physiological information, which will be useful to the reader while reading the later chapters. Although the book discusses predominantly the spinal arachnoid, it also covers important cranial subdivisions of the condition, in addition to associated conditions such as syringomyelia. There is an interesting section on questionable causes of arachnoiditis, which are very relevant because the previously predominant causes-namely, injection of foreign materials into the intrathecal compartment of the spine for diagnostic and therapeutic purposes-are no longer used or are regarded with circumspection. The final sections relate to the thorny question of diagnosis, which is extremely difficult, and to the limited treatment options available. Arachnoiditis is a condition that would be better prevented than treated. Unfortunately, the prognosis remains bleak for these patients but the management strategies in dealing with multiple concerns faced by such patients are well described. The senior author is to be congratulated on producing a single volume, based on some eight thousand references, and his undoubted unique experience of dealing with hundreds of such cases, which is a unique contribution to our body of knowledge.

It is salutary reading for some of the more senior members of our profession and will provide guidance to the younger members. It is a useful book for anyone treating patients with this awful affliction and it can provide guidance to those involved in dealing with patient complaints or litigation. The book provides both philosophical and scientific viewpoints.

J Van Dellen

\section{Texture of the nervous system of man and the vertebrates, volume II}

By Santiago Ramón y Cajal. Translated and edited by Pedro Pasik and Tauba Pasik (Pp 667, US\$150.00). Published by Springe Verlag, Wien, 2000. ISBN 3-211-83201-7

This is the second of three projected volumes that present for the first time in English one of the great classics of microscopical anatomy: Santiago Ramón y Cajal's Texture of the nervous system, which first appeared in Spanish in 1904. The Texture and Sherrington's integrative action of the nervous system, which appeared in 1906, are the two fundamental works from which modern neurological science grew. Hitherto, the Texture was available only in the original Spanish and in the somewhat enlarged French edition of 1911, reprinted in 1952.

This new edition is important, not only because it makes Ramón y Cajal's contribution widely accessible, but also because the translators have gone back to the original illustrations, which are preserved in the Museum of the Instituto Cajal in Madrid. The high quality of the paper compared with that of earlier editions means that much detail is now visible that was formerly obscure. This is well shown by comparing the section of the medulla and cerebellum in figure 238 in the present volume with figure 78 in volume II of the French edition: the beautiful cellular detail is simply not visible in the latter.

Modern investigators are further in the debt of the translators for having provided (and almost always checked) the full references cited by Cajal, correcting errors that had escaped his attention, and annotating the text sparingly but helpfully when modern research had clarified issues that remained unclear to him. The book is beautifully produced and pleasant to hold in the hand.

Ramón y Cajal's work is as central to neurological research today as it was century ago. The translators and publishers deserve our gratitude for bringing this essential work to a new generation of readers.

W I McDonald

\section{Clinical evaluation and management of spasticity}

Edited by David A Gelber and Douglas R Jeffery (Pp 385, US\$125.00). Published by Humana Press, Totowa, 2002. ISBN 0-89603-636-7

This is a useful and interesting book. It is increasingly recognised that several treatment strategies can be beneficial in the management of spasticity, particularly using more recent drugs such as tizanidine and botulinum toxin. The book is a comprehensive review of the subject. No important topics are missed, although the length and thoroughness of the chapters do vary to a significant degree.

The book opens with a brief chapter on the physiology and pharmacology of spasticity. Although the book is targeted towards a clinical audience, and as such is a practical textbook, it is a pity that this opening chapter is so brief with regard to the neurophysiology of spasticity. An understanding of the underlying principles is important for logical treatment. Alex Dromerick produces a good chapter covering the clinical features of spasticity and a brief resume of complications. This is followed by an excellent chapter on the measurement of spasticity by David Good, which I found to be one of the most useful summaries of this field that I have read for some time. My major disappointment in the book is the brevity of the following chapter on physical and occupational approaches. The involvement of a neurological physiotherapist in the management of spasticity is vital and while this chapter is thorough it is too brief and fails to do justice to the key involvement of a physiotherapist in the spasticity team. This defect is partially overcome with an excellent subsequent chapter on orthotic management, which is a very clear and useful overview of an increasingly complex subject. The standard pharmacological interventions (baclofen, tizanidine, dantrolene, and the benzodiazepines) are thoroughly covered in the ensuing chapters with an additional brief chapter on alternative pharmacological therapies. Nerve blocks, botulinum toxin, and intrathecal medications are adequately covered. The chapter by Mary Keenan and Patrick McDaid on orthopaedic interventions for the management of limb deformities in spasticity is the best chapter on this subject I have ever read and certainly should be compulsory reading for the physician who may need to refer to surgical colleagues for the management of complex and drug resistant spasticity.

The problem with these early chapters is that they lack an overall strategic approach to the patient with spasticity. The editors have tried to correct this problem with the last four chapters in the book, which give individual views of the management of spasticity in children with cerebral palsy and in adults with multiple sclerosis, traumatic brain injury, and spinal cord injury. These are useful chapters that bring the rest of the book together, although there is some rather unavoidable repetition. A few illustrative case histories might have been useful in this section. 
Overall this is a thorough, reasonably comprehensive, well referenced, and up to date textbook, which can be recommended to the multidisciplinary spasticity team and is a useful reference for any neurologist.

Michael Barnes

\section{Autoantibodies in neurological diseases}

Edited by Angela Vincent and Gianvito Martino (Pp 160, US\$64.00). Published by Springer-Verlag Italia, Milan, 2002. ISBN 88-470-01 19-6

Antineuronal antibodies were initially de scribed 40 years ago and since then many autoantibodies have been discovered and characterised. Despite this, there is a limited number of texts devoted to the subject of autoantibodies in neurological diseases. Even less common are books that describe autoantibodies and clinical-immunological associations in a manner useful to both clinicians and investigators. This book fills the void. Although the title evokes a laundry list of antibodies this edition offers an even balance between clinical descriptions, immunological mechanisms, and therapeutic implications. The inevitable overlap of topics in a multiauthored book is kept to minimum. An introductory chapter on techniques used for measuring and evaluating the pathogenic role of autoantibodies will be useful for clinicians not directly involved in laboratory research. Subsequent chapters comprehensively cover dis orders of the neuromuscular junction and peripheral nerve and less extensively disorders of the central nervous system associated either with autoantibodies or with other evidence of autoimmunity. Among the latter are chapters on autoantibodies and epilepsy and vasculitis of the central nervous system, topics rarely encountered in other texts. Two chapters on autoimmunity and pregnancy, particularly in association with myasthenia gravis, nicely discuss the effects of immunity on the embryo and newborn. With the exception of disorders associated with antibodies to gangliosides that are not discussed, descrip tions of most of the recently described paraneoplastic and non-cancer related autoantibodies, as well as possible pathogenic mechanisms, are up to date and clear. A chapter on the ontogeny of skeletal muscle cells, although well written, is out of place in this text. The book is well edited and illustrated and the references are thorough. The focus of the text is weighted towards disorders of the peripheral nervous system, likely reflecting the more extensive literature on these disorders. Clinicians and basic investigators in neurology and immunology will find this book an excellent resource.

Joseph Dalmau

\section{CORRECTIONS}

Goertler M, Blaser T, Krueger S, et al. Cessation of embolic signs after antithrombotic prevention is related to reduced risk of recurrent arterioembolic transient ischaemic attack and stroke. J Neurol Neurosurg Psychiatry 2002;72: 338-42.

Single exponential function was erroneously used for the calculation of figure 2 . The correct figure 2 is reproduced below, which shows the predicted probability of recurrent TIA and stroke as calculated from the cumulative underlying hazard and the prognostic index (derived from multivariate regerssion coefficients, mean values of covariables, and number of embolic signals) by double exponential function.

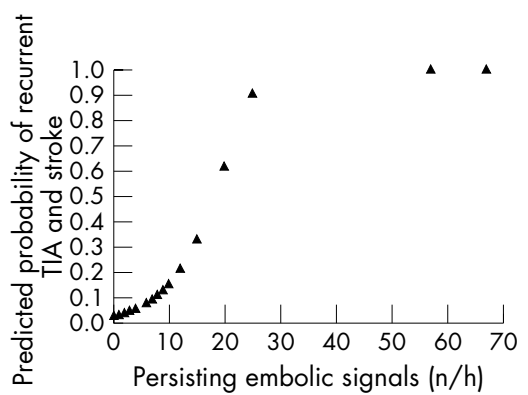

Shorvon SD, van Rijckevorsel K. A new antiepileptic drug. J Neurol Neurosurg Psychiatry 2002;72:426-9. An error has been noted in rows $1-3$ of columns 3 and 4 in table 2 . The correct table appears here.

Table 2 Adverse events (\%) according to FDA and EMEA standards.

\begin{tabular}{llllll}
\hline & \multicolumn{2}{l}{ Adverse reaction* (FDA) } & & \multicolumn{2}{l}{ Undesirable effects† (EMEA) } \\
\cline { 2 - 3 } \cline { 5 - 6 } & $\begin{array}{l}\text { Levetiracetam } \\
(\mathbf{n}=769)\end{array}$ & $\begin{array}{l}\text { Placebo } \\
(\mathrm{n}=439)\end{array}$ & & $\begin{array}{l}\text { Levetiracetam } \\
(\mathrm{n}=672)\end{array}$ & $\begin{array}{l}\text { Placebo } \\
(\mathrm{n}=351)\end{array}$ \\
\hline Somnolence & 15 & 8 & 14 & 8 \\
Asthenia & 15 & 9 & 12 & 9 \\
Dizziness & 9 & 4 & 7 & 3 \\
Infection & 13 & 8 & - & - \\
\hline
\end{tabular}

*Adverse reaction: any event reported during clinical trial; FDA, Food and Drug Administration tundesirable effect: all adverse events at least possibly related to the study drug; EMEA, European Medicinal Evaluation Agency.

Note: Adverse reactions and undesirable effects are derived from three efficacy and one safety, double blind placebo controlled trials. Patient numbers differ because the FDA included the crossover part of the study in the analysis, and some of these patients were counted twice. 